Recepción: 16/10/2016

Evaluación: 17/10/2016

Aprobación: 15/11/2016

Artículo de Investigación Científica

\title{
EL EJERCICIO DEL PODER: EL USO DEL CONSENSO Y LA VIOLENCIA EN PASTO, 1821-1831*
}

\author{
Ingrid Viviana Chaves Martínez** \\ Universidad Pablo de Olavide - Seviila \\ Grupo de Investigación: Historia, Educación y Desarrollo \\ ingridvivianmartinez@gmail.com
}

\begin{abstract}
RESUMEN
Este artículo presenta los resultados parciales de la investigación titulada: Relaciones de poder en Pasto durante la transición del orden colonial al orden republicano, 1821-1831. El objetivo principal de la investigación fue analizar la configuración de las relaciones de poder a partir de la Historia Social como perspectiva teórico-metodológica que permitió articular aspectos sociales, políticos y económicos de la interacción social de la ciudad de Pasto en el contexto político de la Gran Colombia.

En este trabajo se presentan dos características específicas del ejercicio del poder a nivel político y social; en concreto, el uso del consenso de la elite de gobierno local y el uso de la violencia. En medio de la tentativa independentista promovida por la elite quiteña, el retorno del control monárquico, el asedio republicano, los prolongados enfrentamientos militares, el desgate violento de la guerra, la alianza coyuntural entre la elite de gobierno local y el ejército republicano, la ciudad de Pasto pasó de una relación dependiente del poder del imperio español a un nuevo Estado, con cambios políticos y administrativos promovidos por la nueva clase dominante. Desde estas particularidades, el ejercicio del poder tuvo como finalidad establecer un nuevo orden y lograr la subordinación de la población a la nueva autoridad republicana.
\end{abstract}

Palabras clave: Historia social, interacción social, relaciones de poder, Gran Colombia, siglo XIX.

Este artículo forma parte de la investigación titulada: Relaciones de poder en Pasto durante la transición del orden colonial al orden republicano, 1821-1831, en el marco de la investigación doctoral del programa de Doctorado en Historia de América Latina: Mundos Indígenas, de la Universidad Pablo de Olavide, de Sevilla-España.

* Universidad Pablo de Olavide-Sevilla; Grupo de Investigación: HISED-Universidad de Nariño; Historia regional. 


\title{
THE EXERCISE OF POWER: THE USE OF CONSENSUS AND VIOLENCE IN PASTO, 1821-1831
}

\begin{abstract}
This article presents the partial results of the research titled: Power relations in Pasto during the transition from the colonial order to the republican order, 1821-1831. The main objective of this research was to analyze the configuration of power relations from Social History as a theoretical-methodological perspective that allowed to articulate social, political and economic aspects of the social interaction of the city of Pasto in the political context of Great Colombia.

This paper presents two specific characteristics of the exercise of power at political and social levels; in particular, the use of the consensus of the local government elite and the use of violence. In the midst of the independence attempt promoted by the Quito elite, the return of monarchical control, the Republican siege, the prolonged military confrontations, the violent desecration of war, the alliance between the local government elite and the republican army, the city of Pasto went from a relationship dependent on the power of the Spanish empire to a new State, with political and administrative changes promoted by the new ruling class. From these peculiarities, the exercise of power was aimed at establishing a new order and achieving the subordination of the population to the new republican authority.
\end{abstract}

Key words: Social history, social interaction, power relations, Gran Colombia, 19 th century.

\section{O EXERCÍCIO DO PODER: O USO DO CONSENSO E DA VIOLÊNCIA EM PAST0, 1821-1831}

\begin{abstract}
RESUMO
Este artigo apresenta os resultados parciais da pesquisa intitulada: Relações de poder em Pasto durante a transição da ordem colonial para a ordem republicana, 1821-1831. O principal objetivo da pesquisa foi analisar a configuração das relações de poder da História Social como uma perspectiva teórico-metodológica que permitiu articular os aspectos sociais, políticos e econômicos da interação social da cidade de Pasto no contexto político da Grande Colômbia.

Este trabalho apresenta duas características específicas do exercício do poder nos níveis político e social; em particular, o uso do consenso da elite do governo local e o uso da violência. No meio da tentativa independentista promovida pela elite de Quito, o retorno do controle monárquico, o cerco republicano, os prolongados confrontos militares o desgaste violento da guerra, a aliança conjunta entre a elite do governo local e o exército republicano, a cidade de Pasto passou de um relacionamento dependente do poder do império espanhol para um novo estado, com mudanças políticas e administrativas promovidas pela nova classe dominante. A partir dessas peculiaridades, o exercício do poder teve como finalidade estabelecer uma nova ordem e alcançar a subordinação da população à nova autoridade republicana.
\end{abstract}

Palavras-chave: História social, interação social, relações de poder, Gran Colombia, século XIX. 


\section{INTRODUCCIÓN}

El objetivo principal de la investigación fue analizar la configuración de las relaciones de poder en la ciudad de Pasto durante la transición del orden colonial al orden republicano entre 1821 a 1831. Dada la amplitud de la temática, este artículo se limita a referirse a dos características específicas del ejercicio del poder: la primera, de orden político; concretamente, el uso del consenso de la élite de gobierno local a partir de los acuerdos concertados con el ejército republicano en 1822, y, la segunda, de orden social; en particular el uso de la violencia. Estas dos características formaron parte del ejercicio del poder en la adhesión política de la ciudad a la República.

Históricamente, las sociedades han generado prácticas y organizado su espacio en función de los intereses sociales, políticos o económicos, lo que da lugar a relaciones particulares que marcan una determinada época. Para Marc Bloch, "El pasado es, por definición, algo dado que ya no será modificado por nada. Pero el conocimiento del pasado es una cosa en progreso que no deja de transformarse y perfeccionarse"2; en este sentido, el conocimiento histórico de esta región del sur occidente de Colombia es determinante para reflexionar sobre diversas realidades en el presente.

La ciudad vivía un contexto histórico marcado por la resistencia, los intereses de los grupos de poder local y el ejercicio de la violencia, en una sociedad con diferencias sociales y económicas claramente definidas por criterios étnicos y de clase; por tal razón, resulta importante un estudio que busca explicar la configuración de las relaciones de poder en relación con la formación del nuevo Estado, los efectos que se produjeron en la sociedad, los imaginarios y significados utilizados para encauzar la conducta de la población desde el proyecto político promovido por la elite republicana durante la Gran Colombia, un tema relevante y necesario para la comprensión del origen de la vida republicana en la ciudad de Pasto.

La perspectiva teórico-metodológica de esta investigación se enmarcó en la Historia Social ${ }^{3}$. Esta concepción de la Historia permitió el estudio de las relaciones

1. El tema de esta investigación se originó en el trabajo titulado: "Una independencia que amenaza: el realismo en la ciudad de Pasto 1815-1822". Ingrid Viviana Chaves Martínez, Tesis de maestría en el Programa Oficial de Posgrado en Historia de América Latina: Mundos Indígenas, Departamento de Geografía, Historia y Filosofía de la Universidad Pablo de Olavide, de Sevilla, 2012.

2. Marc Bloch, Apología para la historia o el oficio de historiador (México, D.F: Fondo de Cultura Económica, 2001), 82.

3. Teniendo como referencia los aportes teóricos y metodológicos de Lucien Febvre y Marc Bloc, para quienes: "Hay historia sin más, en su unidad. La historia que es, por definición, absolutamente social. En mi opinión, la historia es el estudio científicamente elaborado de las diversas actividades y de las diversas creaciones de los hombres de otros tiempos, captadas en su fecha, en marco de sociedades extremadamente variadas $\mathrm{y}$, sin embargo, comparables unas a otras [...]; actividades y creaciones con las que cubrieron la superficie de la tierra y la sucesión de las edades." Lucien Febvre, Combates por la historia (Barcelona: Ariel, 1970), 39-40. 
de poder, al articular aspectos sociales, económicos y políticos y explicar la configuración de las relaciones que tienen como referencia: la composición social, los grupos de poder local, las características económicas de la ciudad y cómo se dio el ejercicio del poder en la ciudad de Pasto y los efectos derivados del cambio político y administrativo promovido por la elite republicana entre 1821 y 1831.

La revisión documental de fuentes primarias se realizó en el Archivo General de Indias-Sevilla, Archivo General de la Nación-Bogotá, Archivo Histórico del Cauca-Popayán, Archivo Histórico de Pasto, Archivo Parroquial de la Iglesia de San Juan Bautista-Pasto, Archivo histórico de la Notaría Primera del círculo de Pasto, el Banco Central del Ecuador Archivo Jacinto Jijón y Caamaño-Ministerio de Cultura de Ecuador, el Archivo Histórico Nacional de Quito y el Archivo Metropolitano de Quito.

Las fuentes documentales en esta investigación fueron: Actas de cabildo, archivos judiciales y notariales, archivos parroquiales, actos administrativos y políticos, informes, correspondencia, cartas y oficios generados durante la época de estudio. Para la recopilación y clasificación de los datos, se recurrió a la prosopografía como una técnica útil en la investigación histórica. que permitió identificar: datos individuales y familiares, características socio-económicas de los individuos, definir la composición social, los intereses políticos de los grupos de poder local e identificar las acciones que formaron parte del ejercicio del poder local como componente de la nueva autoridad republicana.

\section{PASTO: “LA CIUDAD QUE SE DEFENDÍA”}

Desde la época colonial, la ciudad de Pasto se hallaba entre dos centros de poder: la Real Audiencia de Quito y la Gobernación de Popayán, dependiente del Virreinato de la Nueva Granada. ${ }^{4}$ Esta división de autoridad convirtió a la ciudad en un espacio intermedio y complejo, sobre la base de definir su función en la mediación social, política y económica dentro de sus respectivas áreas de influencia: la Provincia de los Pastos y la Provincia de Pasto y, con respecto a los centros de poder más o menos distantes: Lima, Quito, Popayán y (en menor relación) Santafé. Esta era una posición poco privilegiada si se tiene en cuenta la repercusión de los intereses y los cambios políticos y administrativos de dichos centros de poder.

En relación con la temática de la independencia y la formación de los Estados nacionales en América, se sugiere ver los trabajos de John Lynch, América Latina, entre Colonia y Nación (Barcelona: Editorial Crítica, 2001), 342; Carmen Corona, Ivana Frasquet y Carmen María Fernández, eds., Legitimidad, soberanías, representación: independencias y naciones en Iberoamérica (Castelló de la Plana: Universitat Jaume I, 2009); Beatriz Bragoni y Sara E. Mata, comps., Entre la Colonia y la República. Insurgencias, rebeliones y cultura política en América del Sur (Buenos Aires, Prometeo Libros, 2009); Manuel Chust e Ivana Frasquet, eds., Los colores de las independencias iberoamericanas. Liberalismo, etnia y raza (Madrid: CSIC, 2009).

4. “Calidades de la tierra por Fr. Jerónimo Escobar (Madrid, 1582), Gobierno de Popayán”. En: Fuentes para la Historia Andina, Relaciones Histórico-Geográficas de la audiencia de Quito siglo XVI-XIX, eds. Pilar Ponce Leiva (Quito: Instituto de Historia y Antropología Andina y Abya-Yala, 1992),Vol. 1. 334335. 
Durante el inicio de la República, la ciudad y sus alrededores conservaron el orden colonial, expresado en la diferenciación del núcleo urbano y el rural. La división del espacio permite leer la jerarquía de las relaciones. En el centro urbano, como capital se encontraba el Cabildo, ${ }^{\mathbf{5}}$ sede de la administración política de la Provincia, que convertía a este espacio en el lugar de acción y ejercicio del poder de la elite de gobierno local. ${ }^{6}$ En el área rural, se encontraban principalmente los "pueblos de indios", o parroquias más importantes, ubicadas sobre los límites más cercanos al valle de la ciudad: Pandiaco, Anganoy, Aranda, La Laguna, Cumbachala (Canchala), Tescual, Mocondino, Jamondino, Buesaquillo, Chapal, Catambuco, Obonuco, Gualmatan y Jongobito, ${ }^{7}$ bajo la autoridad espiritual de un cura doctrinero, que ejercía su poder e influencia ideológica a través de los sermones y proclamas; se trataba de una acción sobre la población, que le permitía intervenir en la conducta social y política al enlazar el poder de la elite de gobierno con la movilidad de la gran mayoría de la población. Así, se puede afirmar que se configuró una relación de poder que vinculaba a la elite de gobierno, al clero y al pueblo.

El discurso ilustrado y moderno permite mostrar el imaginario de una ciudad ideal y el contraste de la realidad a través de la separación entre lo rural y lo urbano. El sabio Francisco José de Caldas, al observar la ciudad de Pasto, describió el área rural como "campos verdaderamente poéticos" y resaltó la belleza natural8;

5. El orden republicano estableció las funciones de los cabildos de la siguiente forma: "Art. 57. Son funciones de los cabildos: $1^{a}$ La policía de salubridad, aseo y comodidad. $2^{\underline{a}}$ Auxiliar a los jueces en todo lo que pertenezca á la seguridad de las personas y bienes de los vecinos, y á la conservación del orden público. - 3a La administración é inversión de los bienes de propios y arbitrios conforme a las leyes y reglamentos. - 4⿳亠丷厂 Cuidar de las escuelas de primeras letras, y de los demás establecimientos de educación que se paguen de los fondos común. - 5a Cuidar de los hospitales, hospicios y demás establecimientos de beneficencia. $6^{\underline{a}}$ cuidar de la construcción y reparación de los caminos, calzadas, puentes de necesidad, y utilidad y ornato. $7 \stackrel{\text { a }}{ }$ Promover la agricultura, la industria y el comercio según la localidad y circunstancias de los pueblos, y cuando les sea útil y beneficioso, todo con arreglo á las leyes, reglamentos, ordenes que recibieren." "Título V. De los cabildos y alcaldes de los pueblos". Cuerpo de Leyes de la República de Colombia 1821-1827 (Caracas: Consejo de Desarrollo Científico y Humanístico, Universidad Central de Venezuela, 1961), 81.

6. La Constitución de 1821 estableció a los alcaldes ordinarios y pedáneos como "encargados de la policía, del orden y tranquilidad en sus cantones y parroquias, y guardando la debida subordinación los segundos á los primeros, y todos á los jueces políticos y demás autoridades superiores". "Título V. De los cabildos y alcaldes de los pueblos". Cuerpo de Leyes de la República de Colombia 1821-1827..., 81. A partir de 1823, formaron parte de este grupo de poder Joaquín Paz y Burbano-Juez Político, Crisanto Guerrero-Alcalde $1^{\circ}$, José Soberón-Alcalde $2^{\circ}$, Ramón Córdoba y Figueroa, Salvador OrtizProcuradores.

7. Hermes Tovar et al., Convocatoria al poder del número, Censos y estadísticas de la Nueva Granada (1750-1830) (Bogotá: Archivo General de la Nación, 1994), 332-334.

8. Caldas expresó: "este pueblo oscuro y feliz me llamó la atención, y no cesé de observarlo en los días que me mantuve en él: comencemos por su vista del alto de Aranda. ¡Qué espectáculo tan risueño y magnífico el que presenta la campiña de sus alrededores, la ciudad misma, su horizonte!... una llanura espaciosa de dos a tres leguas, con una ligera inclinación, terminada por colinas de pendiente suave en toda la redondez del horizonte, excepto por el Noroeste, en donde se ve el volcán de tanta elevación, que toca el término de la nieve permanente en la zona tórrida, y que aún humea; todo este terreno cortado por fuentes que reuniéndose forman lo que llaman el río de Pasto; no hay un palmo que no esté cultivado: aquí se ven cuadros dorados (Quito), allí verdes (Pasto), más allá otros actualmente arados; toda la campaña sembrada de casas de campo; cercos vivos, algunos grupos de árboles 
al referirse a la parte urbana, expresó que "era deforme, desgreñada y puerca (...) sus casas malísimamente construidas, oscuras y llenas de inmundicias. (...) hace un terrible contraste con su campaña. (...) Las aguas, aunque cristalinas, tienen la propiedad de dañar el estómago de los pasajeros"9. Para Santiago Castro, "El discurso ilustrado adquiere (...) un carácter etnográfico (...) y el científico ilustrado asume un papel similar al de los cronistas del siglo XVI"10.

El orden espacial de la ciudad se distribuyó en la Plaza Mayor, la casa del Cabildo y Cárcel, siete templos: La Matriz, La Merced, Santo Domingo, San Francisco, San Andrés, Santiago y San Agustín; las capillas: de Jesús, la Panadería y San Sebastián; el monasterio de la Concepción, el colegio que fue de la Compañía de Jesús, las ruinas del hospital; tres vías principales de acceso a la ciudad: Quito, San Andrés, Popayán; seis fuentes hidrográficas: Quebrada de Carachayaca o Caracha, Quebrada de Chapalito, Quebrada de Jesús, Río del Ejido, Río de la Monjas, Río Blanco ${ }^{11}$.

Desde el ámbito cronológico y dado que el periodo objeto de la investigación se identifica como un periodo de transición, es importante mencionar a grandes rasgos las características más significativas del periodo previo, entre 1809 y 1821. Esta fue una época en la cual resultó determinante una representación, generadora de sentidos y significados, en torno a la "fidelidad a la Religión, al Rey y a la Patria"; en esa representación, subyacían relaciones de poder coloniales, que vinculaban al clero, al gobierno y al pueblo, para declarar la lealtad a la "Justa causa" y la resistencia a la "infame junta", lo que entrañaba un conjunto de realidades sociales, políticas y económicas complejas, derivadas de la larga experiencia colonial, una fidelidad a su propia estabilidad y al orden conocido ${ }^{12}$. En este contexto, como lo

frutales, acequias, molinos, y en fin, la ciudad en el centro", “Carta de Caldas" (Quito, 6 de octubre de 1801), Francisco José de Caldas, Cartas de Caldas (Bogotá: Imprenta Nacional, 1917), 96-97.

9. Caldas, "Carta de Caldas", 97.

10. Santiago Castro-Gómez, La Hybris del Punto Cero. Ciencia, Raza e Ilustración en el Nuevo Reino de Granada (1750-1816) (Bogotá: Editorial Pontificia Universidad Javeriana/Instituto Pensar, 2010), 14.

11. Rosa Isabel Zarama Rincón. Vida cotidiana en San Juan de Pasto, 1780-1810 (Pasto: Fondo Mixto de Cultura de Nariño, 2005), 34.

12. El comportamiento y la acción de la sociedad pastusa en defensa de la monarquía española se ha trabajado desde diferentes corrientes históricas que, en su conjunto, permiten una aproximación a ese conjunto de realidades: al tener como punto de partida el desconocimiento de las ideas liberales, debido al aislamiento geográfico de la ciudad en relación con el centro del país, ver Sergio Elías Ortiz, Agustín Agualongo y su tiempo (Bogotá: Editorial ABC, 1958); sobre las características económicas y sociales de Pasto y Barbacoas, ver Jean Pierre Minaudier, "Pequeñas patrias en la tormenta: Pasto y Barbacoas a finales de la Colonia y en la independencia". Historia y espacio. Revista de estudios Históricos Regionales, 3, n 11-12, (enero-diciembre, 1987): 131-165. En: http://bibliotecadigital. univalle.edu.co/xmlui/bitstream/handle/10893/7432/5.\%20Peque nas\%20patrias\%20en $\% 20$ la\%20tormenta\%20Pasto\%20y\%20Barbacoas\%20-\%20Minaudier\%20Jean.pdf?se quence=1; la actitud político-militar del pueblo durante la guerra de independencia, ver Gerardo Guerrero, Pasto en la Guerra de Independencia 1809-1824 (Bogotá: Tecnimpresores, 1994), 195; las Faces del “Realismo", "La primera es una conducta de defensa del territorio ante la invasión patriótica 1809. La segunda conforma una lucha frontal contra las fuerzas patriotas que quieren obligar al pueblo pastuso a "muda de opiniones". En la tercera y última fase, llega la radicalización de la resistencia ante la presión patriota, que pregona y ejecuta "la guerra a muerte" contra los pastusos, ver Lydia Inés Muñoz Cordero, El Consejo de Pasto a través de la Historia (San Juan de Pasto: Editorial Universitaria Universidad de Nariño, 2000), 50; Jairo Gutiérrez Ramos muestra cómo los indios de Pasto establecieron lazos de solidaridad étnica y estrategias de acción política que encontraron su máxima forma de expresión 
expresa John Lynch, era "más probable que una sociedad acepte la ausencia de derechos que nunca ha experimentado que la pérdida de derechos que ya había disfrutado"13. La elite de gobierno local expresó claramente su desacuerdo con las Juntas de los rebeldes de Quito y la Nueva Granada y, desde 1809, se declaró en alerta y defensa del orden colonial ${ }^{\mathbf{1 4}}$. Esta elite se vio a sí misma con el derecho y la obligación de llevar a cabo una serie de acciones y conducir al pueblo hacia la lealtad y la resistencia, desde una relación de subordinación.

El periodo de transición, entre junio de 1821 y 1831, fue el inicio de un proceso mediante el cual Pasto dejó atrás la forma de gobierno colonial y pasó a regirse por el orden político de la Gran Colombia, plasmado en la Constitución de 1821;

a través de las rebeliones antirrepublicanas, en Jairo Gutiérrez Ramos, "Acción política y redes de solidaridad étnica entre los indios de Pasto en tiempos de la Independencia". En: Historia Crítica, 33 (enero-junio 2007), http://www.scielo.org.co/pdf/rhc/n33/n33a02.pdf (10 de octubre de 2012); y Los indios de Pasto contra la República (1809-1824) (Bogotá: Instituto Colombiano de Antropología e Historia. 2007), 274; Marcela Echeverri hace un trabajo sobre la defensa realista por parte de indios y esclavos en la provincia de Popayán, desde 1808 hasta 1820, quienes, durante la crisis de la monarquía, buscaron beneficiarse del contexto político y dar nueva forma a sus derechos a través de la alianza con los realistas. Marcela Echeverri, "Los derechos de indios y esclavos realistas y la transformación política en Popayán, Nueva Granada (1808-1820)”, ver Revista de Indias 69, n.o 246, (2009):45-72; desde el entramado familiar del poder, Dúmer Mamián hace un análisis que considera la postura de la "nobleza" pastusa frente a las opciones autonomistas, independentistas y republicanas y trata de mostrar que en los "nobles" pastusos existió la ambición de un polo de desarrollo diferente, de acuerdo a su tradición y a las circunstancias geográficas, históricas y políticas; ver Dúmer Mamián, "Rastros y rostros del poder en la Provincia de Pasto Primera mitad del Siglo XIX, "Leales a sí mismo" (tesis doctoral, Universidad Andina Simón Bolívar de Quito, 2010); ver Carol Guerrero y Gerardo Guerrero, El honor en Pasto durante la Independencia: "la defensa de la Santa Causa" (Pasto: Universidad de Nariño/Ceilat, 2011), 163, entre otros.

13. Lynch, América Latina, entre Colonia y Nación, 136.

14. "Los señores de este ilustre Cabildo, Justicia y Regimiento que aquí firman, estando juntos y congregados para tratar y conferir las cosas correspondientes al servicio de Dios nuestro señor, del Rey y del bienestar de la patria, especialmente para abrir un pliego titulado a este ilustre Cabildo, indicando ser del Presidente de la Junta Suprema, que se creyó ser de la Nacional, habiéndolo leído con el mayor horror encontraron contener la formación de otra en la ciudad de Quito, cuyo Presidente pretende seducir la fidelidad notoria y perpetua de este noble cuerpo y sus ciudadanos que con la más sumisa deferencia han jurado el vasallaje a su Soberano y Suprema Junta que lo representa: en cuya virtud han deliberado que con extraordinario que adelante las jornadas, se dé cuenta al señor Gobernador y Comandante General de la Provincia con el mismo oficio (quedando copia) y con copia de esta acta, para que se sirva de dictar las más prontas y oportunas providencias al efecto de poder contrarrestar a las infames pretensiones de que aquella malvada Junta, sirviéndose de darla igualmente comunicándonos auxilios de armas, municiones y tropa; respecto de estar este lugar y sus vecinos destituidos enteramente. Y para precaver entre tanto algunos resultados de la intriga, cavilación é insurrección que pueda despachar algunas fuerzas con el objeto de forzarnos (que no lo conseguirán a menos de derramar la última gota de sangre en defensa de la Religión, del Rey y sus legítimas Potestades), pásese inmediatamente oficio al Corregidor de la Provincia de los Pastos con copia de él de la infame junta para que se vigile, sobre si se remite alguna incursión de tropas, ó se trata de ella; y en tal caso, lo avise con la mayor celeridad, y aliste las gentes que se estimaren de lealtad para la resistencia. Y por lo que respecta esta Ciudad, se comete el realizarlo al señor Alcalde de primera nominación (que provisionalmente se le nomina Jefe) teniéndose la satisfacción de que no faltará alguno que se presente a la defensa de la Justa Causa, por su notoria lealtad y el ánimo inflamado que se ha reconocido á vista de las primeras noticias de este caso escandaloso". La élite de gobierno local que firmó la conformaron Pedro Pasqual Aramburu y Amado, Matías Ramos, Gabriel de Santacruz y Caicedo, José Pedro Santacruz, y Francisco Miguel Ortiz, José de Vivanco, Miguel José Arturo-Escribano de Cabildo público y de Real Hacienda. "Acta Capitular". (Pasto, 16 de agosto de 1809). En Gustavo Guerrero, Documentos Históricos de los hechos ocurridos en Pasto (Pasto: Imprenta Departamental, 1912),1-2. 
un periodo caracterizado por la inestabilidad política y un contexto marcado por las guerras civiles, que culminó con la formación del Ecuador como República independiente, en 1830. A nivel local, desde el ámbito político, fue significativa la firma de las capitulaciones entre Basilio García y Simón Bolívar, en 1822, hecho dado en un ambiente amenazador y violento, que articuló viejas y nuevas relaciones de poder vinculadas con el cambio; desde un discurso de la resistencia hacia el discurso de la "paz, la tranquilidad y el orden", se produjeron sentidos y significados a partir de los temores e inquietudes reales o imaginarios y acciones frente al pueblo ${ }^{15}$, en tanto responsable de alterar el orden social.

Desde el ámbito social, los censos de población de la jurisdicción de Pasto, correspondientes a los años de 1779, 1780, 1788 y 1797, mostraban la tradición de una estructura social jerárquica fundamentada en la "distinción entre sexos, estados, clases y castas"16; según el censo de 1797, la población de la jurisdicción de Pasto, a finales del siglo XVIII, era de 12.461 habitantes, distribuidos de la siguiente manera:

Gráfica 1. Censo de Población del año 1797.

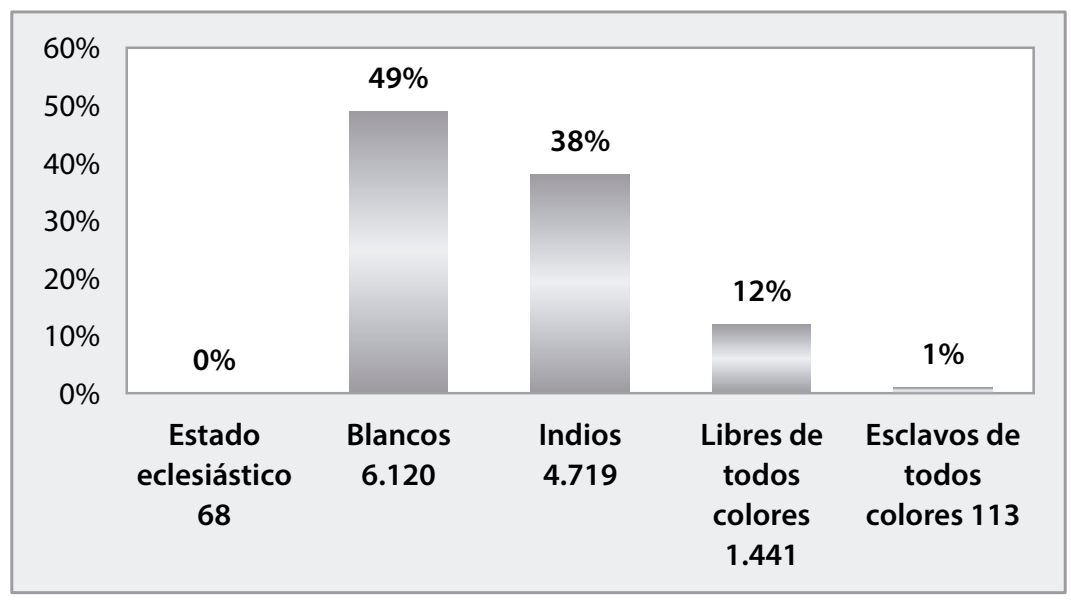

Fuente: Esta investigacion, con base en Hermes Tovar Pinzón, et al., 319-22.

15. Sobre el pueblo, o la plebe, expresa Scarlett O’Phelan Godoy que: “fue (...) durante el siglo XVIII cuando surgió el termino plebe para referirse a las capas bajas de la población compuesta por indios, negros y castas, se consideraba por ser individuos de «mala raza» porque, debido a sus subsecuentes mezclas raciales, carecían de lo que se denominaba la «pureza de sangre». De allí que se los mantuviera a distancia, infringiéndoles un sentimiento de marginalidad. Las castas y la plebe eran vistas como alteradores del orden público; individuos de escasos recursos, con trabajos eventuales o desocupados y, por lo tanto, proclives al ocio, al robo, a la violencia, a la insubordinación." Scarlett O’Phelan Godoy, "La construcción del miedo a la plebe en el siglo XVIII a través de las rebeliones sociales". En: El miedo en el Perú Siglos XVI al XX, ed. por Claudia Rosas Lauro (Lima: Fondo Editorial Pontificia Universidad Católica del Perú, 2005), 124.

16. Tovar, et al., Convocatoria al poder del número..., 305-21. 
Esta gráfica permite poner en perspectiva las características de una configuración social fragmentada a partir de su origen étnico, en la que sobresalía la población blanca e indígena; el clero y la población esclava representaban menor proporción y, al tener en cuenta la importancia del origen étnico y el color, como elementos que permitían la clasificación social de la población, se puede reconocer la precensia de la población, que era resultado de la mezcla. Desde el punto de vista de la clase, Sergio Elias Ortiz afirmó que la presunción de superioridad de una clase sobre otra marcaba las distancias sociales; al respecto señaló:

La de los blancos de "Castilla", que se tenían por nobles, sin mezcla de sangre, de solar conocido y, si acaso, con algún pergamino conseguido tras largas gestiones en España y a precio de buen oro; los blancos de la "tierra", gentes venidas a menos o ya mezcladas con sangre plebeya que formaban una especie de término medio entre la nobleza y el pechero; el pueblo, o sea la masa que desempeñaba los trabajos serviles, herreros, albañiles, canteros, plateros, pintores, escultores, músicos, zapateros, fundidores, tejeros, barberos, seilleros, etc.; el indígena, reducido a resguardo, considerado como menor de edad y a quien se le permitía poseer un pedazo de tierra a título enfitéutico o útil; el concierto o peón de las haciendas que estaba en peores condiciones que su hermano de los reguardos y el esclavo africano, negro bozal, o ya diluido en zambo y mulato, según la mezcla que le había cabido en suerte ${ }^{\mathbf{1 7}}$.

En este contexto, resulta importante considerar que si la Batalla de Boyacá, en 1819, significaba el triunfo libertador de la Nueva Granada, la ciudad de Pasto aún era impenetrable ${ }^{18}$ y se hallaba en "estado de guerra"19; aunque su seguridad se veía amenazada por el asedio del ejército libertador, se puede afirmar, como lo expresa José Luis Romero, que Pasto era "la ciudad que se defendía (...) también una ciudad que atacaba. Mientras esperaba prevenida al enemigo, organizaba nuevas expediciones para ocupar el territorio circundante o las regiones que estaban bajo su influencia o sobre las rutas que convergían en la ciudad"20. En enero de 1821, Basilio García informó a Melchor Aymerich que los habitantes de la provincia de Pasto y los del Valle del Patía se encontraban preparados para el ataque de los insurgentes $^{21}$; todos los habitantes de esta ciudad, su jurisdicción y provincia de

17. Ortiz, Agustín Agualongo y su tiempo, 24.

18. En una de las cartas dirigidas por el Obispo Salvador a Pío VII le expresó: "poco después de la llegada de los soldados españoles, el ejército de la república amenazó a Popayán, y nos fue necesario abandonarla con el ejército y oficiales reales, y marchar a Pasto, ciudad segurísima y fortísima, por rocas y barrancos inaccesibles que la rodean y sobre los que está fundada y asentada. Seguros allí de toda invasión exterior, nuestro ejército podía engrosarse y fortalecerse por la fidelidad del pueblo para con su Rey." (19 de abril de 1823). En Boletín de Estudios Históricos, 3, nº 32 (1930):236-37.

19. Esta particularidad significaba que el pueblo, y no el Gobierno, debía sufragar los gastos del ejército. "Comunicado de Blas de la Villota, Alcalde de primera nominación dirigido al Cabildo de la ciudad", (Pasto, 18 de febrero de 1819), Instituto Municipal Archivo Histórico de Pasto (IMAHP), Fondo Cabildo de Pasto, Sección Independencia, Caja 10, Libro 1819, f. 40-41.

20. José Luis Romero, Latinoamérica. Las ciudades y las ideas (Buenos Aires: Siglo XXI, 2014), 81.

21. "Nada menesterosa es pues [la tropa] con la que aquí tengo, y la disposición de todo el pueblo, y provincia considero suficiente para concluir con el enemigo si se atreviese a llegar aquí, pues su entusiasmo es grande, y no tan solo cuento con Pasto, y su jurisdicción, sino también con la Provincia 
los Pastos, se hallan alineados y prontos a defenderse de los enemigos ${ }^{22}$; de otra parte, el cura de San Pablo, Don Ángel Sarmiento, informaba al obispo Salvador Jiménez, y éste a Melchor Aymerich, al decir que: "ya estaba convenido con todo su pueblo a salir a batir al enemigo, y que le diese licencia para acompañarlos, —dice el obispo- como en efecto ya se la he dado: el mismo entusiasmo vecina por todo el valle del Patía"23.

De Pasto y la provincia salieron 728 hombres hacia el Juanambú, organizados y comandados por los oficiales: Pedro Tola, Juan Carcaño, Antonio Merchancano, Joaquín Enríquez, José Rosero, Estanislao Merchancano, José Polo, José Folleco, Pedro Santacruz, Ysidro Villarreal, Miguel Puente, Francisco Ibarra, Nicolás

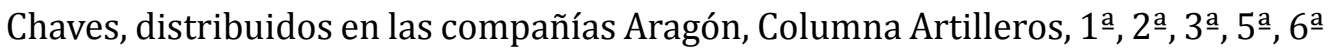
de Funes, 7 ${ }^{a}$, Granaderos de Yacuanquer, Voluntarios emigrados, Patía y Correos ${ }^{24}$.

\section{EL EJERCICIO DEL PODER Y EL USO DEL CONSENSO: "LAS CAPITULACIONES DE 1822"}

Desde el ámbito político, resulta importante mostrar cómo, a partir de febrero de 1821, se posibilitó la reconfiguración de una relación de poder, una relación que en principio se caracterizó y utilizó el consentimiento y aceptación de la elite local y propició la transformación de una forma particular de discurso que hasta el momento se había caracterizado por la defensa y la resistencia, para cambiar hacia un discurso con la pretensión de lograr la paz, la tranquilidad y el inicio de un nuevo orden; el cambio de una relación de poder que se había subordinado al orden colonial por la subordinación a la nueva autoridad republicana.

En esta reconfiguración del poder local, fue determinante el papel y la mediación que tanto el oficial español Basilio García como el Obispo Salvador Jiménez desempeñaron para posibilitar los acuerdos políticos entre la elite de gobierno local y el ejército republicano.

Con ocasión del paso de los oficiales republicanos Antonio Morales y José Morales por la ciudad de Pasto, para dirigirse a Quito, se evidenciaron las sospechas y la desconfianza en el pueblo, según lo señalaba el oficial republicano Antonio Morales, debido a "algunas cartas [de Sucre] cogidas a Valdés, quien anduvo

que está dispuesta a defender la causa del Rey”. "Parte dirigido por Basilio García a Melchor Aymerich" (Pasto, 1 de enero de 1821), Archivo Nacional de Ecuador (ANE), Fondo Presidencia de Quito, Caja 234, Vol. 1, f. 2

22. "Informe de Basilio García a Melchor Aymerich". (Pasto, 3 de enero de 1821). (ANE), Fondo Presidencia de Quito, Caja 234, Vol. 1, f. 13.

23. “Comunicación de Salvador Jiménez a Melchor Aymerich". (Pasto, 5 de enero de 1821). Archivo Nacional de Ecuador (ANE), Fondo Presidencia de Quito, Caja 234, vol. 1, f. 25.

24. "Estado que manifiesta por compañías la fuerza que existe en los puntos de Juanambú con expresión de los que las mandan" (Campo Matabajoy, 29 de enero de 1821). (ANE), Fondo Presidencia de Quito, Caja 234, vol. 1, f. 94. 
muy incauto"25; con la intención de contener al pueblo, Basilio García dirigió una comunicación, en la que expresaba lo siguiente:

Los emisarios enviados por los Gobiernos españoles y de la República han llegado a esta ciudad y me han manifestado las credenciales del armisticio por seis meses (...)

En esta virtud descansad en el Gobierno que tiene cuidado de conservaros y de mantener en su fuerza y vigor los derechos del Rey; y por tanto cesad de reuniros, y retiraos a vuestras casas a descansar y cultivar vuestras heredades, sin temor de que los enviados vengan de mala fe, pues en este caso el Gobierno no les habría dado entrada en vuestro territorio, y antes si los habría apresado y castigado su intriga; pero estando satisfecho de lo contrario, pues tengo a la vista los oficios del General Murillo, que conozco muy bien, lo mismo que la de su Secretario Caparros; en esta virtud os repito que descanséis en las operaciones y medidas del Gobierno que en todo desea vuestro mayor beneficio y felicidad, y en su consecuencia y garantía prometida a los emisarios han internado en este país con sólo el objeto de la paz, demostrándolo con venir solos y sin escolta alguna ${ }^{26}$.

Es importante señalar la contradicción de mantener los derechos del rey como una forma de tranquilizar y contener al pueblo; con la desconfianza, también empezó a generarse temor en la gran masa, en las autoridades de gobierno y en el propio ejército español.

Estos hechos no se pueden explicar al margen del poder ideológico que el clero ejercía. Desde la época colonial, este grupo social había tejido una trama de poder articulada con la "jurisdicción espiritual" a través de los curatos o parroquias. Los curas, en cada pueblo, en algunos casos subordinados al obispo, en otros dadas sus deliberadas inclinaciones clientelares con la elite de gobierno local, dirigieron la conducta de los individuos hacia la resistencia ${ }^{27}$; una vez firmada la adhesión

25. Una de las cartas de los oficiales republicanos describe el estado en el que se encontraba la ciudad y el pueblo después del enfrentamiento militar de Genoy: “Ayer he llegado a ésta acompañado de un batallón de pastusos armados, de don Basilio García, que hace de Gobernador Comandante General, de varios Oficiales españoles que salieron a recibirme, del Cabildo y del Clero. Las calles estaban cubiertas de un inmenso pueblo que gritaba sin cesar “¡viva nuestro Rey don Fernando Séptimo!” Una monja gritó: “imueran los insurgentes!” y lo mismo hizo una mujer del bajo pueblo. Este estaba lleno de desconfianza de mi mensaje y en una grande fermentación que se traslucía bastante a pesar de activas y prudentes medidas que para sofocarla había tomado de antemano don Basilio y de las públicas exhortaciones de su Ilustrísima. Pero a pesar de todas estas medidas hoy ha vuelto el pueblo a conmoverse y ha sido necesario que el señor Obispo y don Basilio ocurriesen luego a nuevas precauciones y les hiciesen ver los documentos con que está acreditado nuestro mensaje, pues desconfían absolutamente de nuestra buena fe". "Carta de Antonio Morales dirigida a Antonio José de Sucre". (Pasto, febrero 11 de 1821). En Boletín de Estudios Históricos 2, n 14 (1928):42.

26. "Comunicación de Basilio García dirigida al pueblo pastuso". (Pasto, 10 de febrero de 1821). En Boletín de Estudios Históricos 2, n 14 (1928):43.

27. Entre las estrategias utilizadas por el clero para movilizar a la población estuvo comunicar los triunfos realistas a través de los curas de cada pueblo, lo cual se utilizó en las misas y predicaciones para persuadir a la población hacia la resistencia. El mismo Obispo Salvador Jiménez, en una de las comunicaciones remitidas a Melchor Aymerich, en relación con el triunfo de "Loma Verde", expresó 
a la República, su papel fue promover el orden, la tranquilidad y la obediencia de la población a la nueva autoridad. La característica particular de este poder estuvo en guiar la conducta, la conciencia y las ideas ${ }^{\mathbf{2 8}}$, en este caso en beneficio de la elite de gobierno; se podría decir que la administración espiritual constituyó un instrumento articulador de los poderes social y político.Por su parte, la comunicación del obispo expresaba lo siguiente:

valientes y fieles pastusos:

El obispo de boca y en qué tan repetidas pruebas os tiene dadas del amor que os profesa y de su fidelidad acendrada, se ve obligado para disipar los temores que quizá algunos malvados e ignorantes os han infundido contra los enviados por los gobiernos de Colombia y español para pasar a Quito a arreglar con aquel señor Presidente los tratados de suspensión de armas, a deciros que estos emisarios vienen de buena fe, como consta en los documentos que nos han presentado; que su venida nos debe ser muy favorable y que cualquier agravio por pequeño que sea que se les hiciese a sus personas nos causaría las más fatales consecuencias; descansad en mi palabra y haced ver que si sois valientes en la guerra, también sois generosos y urbanos con los que vienen de paz $^{29}$.

Esto permite mostrar la dinámica cambiante de esta época; de la resistencia y defensa del orden colonial se pasó a un discurso que buscaba contener al pueblo; la comunicación indica la percepción que el obispo tenía respecto a la existencia de la desconfianza en el pueblo; esta desconfianza no solo puede verse en relación con los emisarios republicanos; además, relacionada con la elite local que, de un momento a otro, después de alentar a la guerra, pretendía re-convenirlos a la quietud y al cese de las hostilidades; asimismo, el cambio de este discurso empezó

que había enviado un comunicado: "sobre la brillante y famosa victoria de Verde Loma, encargándome lo haga circular a todos mis curas de los pueblos (...) para que lo participen a sus fieles feligreses, y den gracias al Dios de los exércitos por lo visiblemente que protege nuestra santa causa (...) lo hice circular a todos mis curas, mandándoles celebrar una misa solemne de gracias con Te Deum y que les hiciesen una exortación con el mismo objeto de que V.E. me previene, pues que lo haga muy conducente para animar a los fieles. [El obispo detalló sus pareceres y prácticas utilizadas para animar al pueblo a pelear contra el ejército republicano]. "En esta ciudad [Pasto] de acuerdo con el Señor Gobernador habíamos resuelto celebrar el día de mañana una misa de acción de gracias con Te Deum, y predicar yo sobre los triunfos de la famosa victoria de Verde Loma como lo hice quando la de Guachi, mas después nos ha parecido mejor hacer una solemne novena a Nuestra Señora de las Mercedes trayéndola a la Matriz, en la que predicare todas las noches para entusiasmar más y más a estas gentes, que a Dios gracias están muy animados para pelear y los vecinos pudientes se prestan gustosos al suministro de los alimentos de la tropa, a cuyo efecto hemos instalado una junta de protección de orden de este Señor Gobernador, para proporcionar los abastos compuesta de los principales sujetos de la que se me ha hecho presidente". "Comunicación dirigida por Salvador Jiménez de Enciso a Melchor Aymerich" (Pasto, 5 de enero de 1821), (ANE), Fondo Presidencia de Quito, Caja 234, Vol. 1, f. 25-26.

28. Similar a lo analizado por Michel Foucault como el poder pastoral, "un poder de origen religioso, que es el que pretende conducir y dirigir a los hombres a lo largo de su vida", en el caso de Pasto no solamente ligado a la subjetividad y los imaginarios sobre la salvación, el más allá o la individualidad, sino, también, en función de los intereses de quienes ejercían el poder político local. Ver Michel Foucault, Estética, ética y hermenéutica. Obras esenciales (Barcelona: Paidós, 1999), Vol. 3:124-28.

29. "Carta de Salvador, Obispo de Popayán al pueblo pastuso" (Pasto, febrero 10 de 1821). En Boletín de Estudios Históricos 2, n 14 (1928):43-44. 
a perfilar al pueblo como alterador del orden y se podría afirmar que al pueblo también se le temía.

El obispo, después de que había movilizado a la población para resistir al enemigo republicano, se enfrentaba de algún modo a tomar una decisión; dirigió una comunicación a Simón Bolívar, ${ }^{30}$ que permite ver cómo empieza a cambiar y construirse un discurso sobre el pueblo, en el que se lo identificaba como "indócil", "perturbador de la tranquilidad pública" y responsable de "todos los horrores de la guerra".

Las circunstancias hacían insostenible la resistencia y la carta del obispo permite ver la táctica de negociación con Bolívar; detrás de la sumisión y rendición, estaba la conciencia de ofrecerle sus "servicios", necesarios para el proyecto republicano; en caso de que abandonara el territorio, el obispo también le ofrecía, a Bolívar, la "utilidad" de sus servicios, desde España o desde Roma. Cualquiera que fuese, la decisión no afectaría a su persona ni su integridad. Por su parte, Bolívar se mostró agradecido respecto a las consideraciones hechas hacia él, al reconocer el valor de las convicciones del religioso y, al mismo tiempo, le recordó sus deberes con la Iglesia, le expresó la solicitud de que no abandonara a las “ovejas afligidas” y prestara sus servicios al gobierno republicano ${ }^{31}$.

30. Excelentísimo señor: me apresuro a rendir a V.E. mis respetos, sumisión y obediencia.

Confiado en la bondad y generosidad de V.E., y para aquietar a algunos mozos indóciles de este pueblo que sin conocer sus verdaderos intereses pudieran perturbar la tranquilidad pública, atrayendo sobre los conciudadanos pacíficos todos los horrores de la guerra, he permanecido en esta ciudad sin querer tomar otro ningún partido, lisonjeándome de que V.E. no dejara de dispensarme la protección que me tiene ofrecida.

(...) Mi provisor y secretario van encargados de conferenciar con V.E. acerca del ceremonial con que de parte de los eclesiásticos deba ser recibido, para que en todo sea complacido y obsequiado cual es debido a su alta representación. Por motivos poderosos que me asisten de conciencia y políticos, sólo deseo que V.E., usando de su generosidad, me conceda la gracia de darme mi pasaporte para regresar a mi país, en donde sólo apetezco vivir retirado en el rincón de un claustro, para concluir mis días en tranquilidad y reposo. Esta misma solicitud hace tiempo la tengo hecha al gobierno de España, y creo que a la hora de esta se me habrá concedido habiéndome admitido la renuncia tengo hecha de mi obispado. Si V.E. me concede, como espero, el pasaporte yo puedo ser útil tanto en la corte de España como en la de Roma, para procurar los intereses de la República de Colombia, yo me honraré con la confianza que V.E. hiciese de mí, bajo la segura confianza de que soy hombre de honor y de carácter que no faltaré a mis promesas y haré cuanto pueda en favor de estos pueblos, a quienes he amado desde mi juventud y los amaré hasta la muerte. Deseo que V.E. reciba con benignidad los sinceros votos de mi corazón, y que mande cuanto sea de su superior agrado a este sus más fino, humilde súbdito, servidor y capellán. "Carta de Salvador Obispo de Popayán dirigida a Bolívar" (Pasto, 7 de junio de 1822). En Boletín de Estudios Históricos 3, nº 32 (1930):237-38.

31. La carta decía: "Ilmo. Señor, yo quiero suponer que V.S.I. está apoyado sobre firmes y poderosas razones para dejar huérfanos a sus mansos corderos de Popayán: mas no creo que V.S.I. pueda hacerse sordo al balido de aquellas ovejas afligidas y a la voz del Gobierno de Colombia, que suplica a V.S.I. que sea uno de sus conductores en la carrera del cielo. V.S.I. debe pensar cuántos fieles cristianos y tiernos inocentes van a dejar de recibir el sacramento de la confirmación por falta de V.S.I.; cuántos alumnos de la santidad van a dejar de recibir el augusto carácter de ministros del creador, porque V.S.I. no consagra su vocación al altar y a la profesión de la sagrada verdad. V.S.I. sabe que los pueblos de Colombia necesitan de curadores, y que la guerra les ha privado de estos divinos auxilios por la escasez de sacerdotes. Mientras S.S. no reconozca la existencia política y religiosa (...) de la nación colombiana, nuestra Iglesia ha menester de los Ilmos. Obispos que ahora la consuelan de esta orfandad para que llenen en parte esta mortal carencia. (...) Yo me lisonjeo que V.S.I., considerando lo que llevo expuesto, 
Así como el líder religioso había sido útil para la resistencia, a partir de esas negociaciones lo fue para continuar cumpliendo su labor y contribuir con la administración espiritual que requería la República; el mismo obispo afirmó: "cuando el Excmo Libertador se dignó visitarme y exponerme de nuevo los argumentos fortísimos que había tocado en su carta, al momento determiné volver a mi diócesis y prestar sumisión y obediencia a la república de Colombia, para poder así emprender nuevamente los trabajos de mi ministerio apostólico; ${ }^{32}$ en la carta dirigida a Bolívar le expresó: "me someto en un todo a la voluntad de V.E., y estoy pronto a permanecer en el territorio de la república, presentándole mi más sumisa obediencia, por tal de cooperar en cuanto mis fuerzas alcancen a que prospere en nuestros países el tesoro inestimable de la religión de Jesucristo". ${ }^{33}$.

El cumplimiento de esta alianza entre Bolívar y el Obispo se hizo efectivo cuando el Congreso de la República, mediante el Decreto de 28 de julio de 1823, declaró al obispo en uso de sus facultades episcopales, ${ }^{34}$ pues antes, mediante Decreto de 31 de agosto de 1821, el Congreso, después de pedirle su adhesión a la causa republicana y en vista de las enérgicas negativas del obispo, lo había sustituido y había declarado vacante el obispado de Popayán, para nombrar en su lugar a Manuel María Urrutia ${ }^{35}$.

En lo referente a la firma de las Capitulaciones, se dieron en un contexto tenso, de difíciles condiciones para el ejército español y para la población, con la amenazadora advertencia de Bolívar, que, entre otras cosas, decía:

Es por última vez que dirijo a V.S. palabras de Paz. Muchos pasos he dado para evitar a V.S., a esa guarnición y al desgraciado pueblo de Pasto todos los horrores de la guerra; pero la medida de la obstinación ha llegado a su colmo, y es necesario, ó que V.S., esta guarnición y el pueblo de Pasto entren por una capitulación honrosa, útil y agradable, ó que se preparen a vencer o moririn.

En este contexto, Bolívar reiteró la propuesta de una capitulación para los pastusos, por la cual quedaban:

Primero: Indemnizados de todo cargo y responsabilidad aquellos contra los cuales tenemos ultrajes que reclamar. Segundo: las tropas que quieran volver al territorio español serán remitidas con sus bagajes y propiedades donde quiera que gusten ir. Tercero: el pueblo de Pasto será tratado como

se servirá condescender con mi ardiente solicitud, y que tendrá la punta de aceptar los cordiales sentimientos de veneración que le profesa su atento obediente servidor". "República de Colombia, Simón Bolívar, libertador Presidente de la República" dirigida a Salvador, Obispo de Popayán, (Cuartel General de Pasto, 10 de junio de 1822). En Boletín de Estudios Históricos 3, n 32 (1930):239-40.

32. "Carta de Salvador, Obispo de Popayán dirigida a Pío VII", 19 de abril de 1823, en Salvador, Obispo de Popayán. En Boletín de Estudios Históricos 3. N 32 (1930):240-41.

33. "Carta del Obispo Salvador Jiménez de Enciso dirigida a Simón Bolívar" (Pasto, 7 de junio de 1822). En Boletín de Estudios Históricos 3, nº 32 (1930):241.

34. Cuerpo de Leyes de la República de Colombia 1821-1827..., 153.

35. Cuerpo de Leyes de la República de Colombia 1821-1827..., 41-44.

36. “Confesiones de Basilio García”, Cuartel general del Trapiche, 23 de mayo de 1822. En Ignacio Bolívar Usobiaga. El libertador y el tratado en Pasto (Sevilla: s.e., 1980), 20. 
el más favorecido de la república, y no pondremos ni guarnición siquiera si entrega sus armas y se restituye a una vida pasiva. Cuarto: el pueblo de Pasto tendrá los mismos privilegios que el de la capital de la república en todos sus derechos respectivos. Quito: Los españoles, sean militares o civiles, si quieren jurar fidelidad al gobierno de Colombia, serán colombianos, conservándoles sus empleos y propiedades ${ }^{37}$.

Tanto Bolívar como el cabildo de la ciudad reconocieron la generosidad de la propuesta; se debe advertir que la prioridad de ese momento, para Bolívar, era avanzar sobre Quito y el Perú, lo que posiblemente propiciaba una mayor disposición a capitular que a generar un desgaste militar, más necesario en la campaña libertadora del Perú.

Basilio García convocó al Ayuntamiento de la ciudad y en Cabildo abierto, del 28 de mayo de 1822, se leyeron el oficio de Bolívar del 23 de mayo y el pliego que contenía la negociación; según el Acta, se sometió a votación; el Cabildo consideró que las capitulaciones propuestas estaban "revestidas bajo del carácter más filantrópico"; sin embargo, la elite de gobierno, que ejercía el poder político local, dejó constancia de sus intereses económicos, relacionados con la conservación de sus bienes y propiedades, la garantía de las personas y bienes de la tropa veterana y vecinos de Pasto; que sus habitantes se conservaran en clase de urbanos y no se desterraran a otros lugares; la exención del pago de contribuciones económicas, la conservación de sus costumbres religiosas, el trato humano a los moradores de la ciudad, el establecimiento de la Casa de la moneda, el respeto de la alta dignidad del obispo y demás clérigos; estos acuerdos incluían al territorio del Patía; en estos términos, la elite de gobierno local expresó sus intereses particulares, su consentimiento y rendición al ejército y al gobierno republicano ${ }^{38}$.

En lo referente al documento definitivo de las capitulaciones ${ }^{39}$, resulta importante mencionar que, a través de los 11 artículos, casi en su totalidad se concedieron las pretensiones planteadas por los miembros del Cabildo, salvo dos

37. Bolívar Usobiaga, El libertador y el tratado en Pasto, 21.

38. "En cuya virtud, y no dudando esta corporación y pueblo reunido que el Ecsmo. señor presidente el Libertador acepte las ampliaciones antecedentes, se somete a lo capitulado, confiando en que así S.E. ha cumplido religiosamente en Cartagena y demás lugares que ha reconquistado, lo verifique con esta ciudad, atendiendo a la ninguna repugnancia que ha tenido para someterse a su gobierno luego que ha conocido la piedad de sus intenciones". La elite de gobierno local que firmó el acta para que se incluyera en las capitulaciones la conformaron el jefe-político Ramón Zambrano, Francisco Santacruz de Barona, Pedro José Guerrero, Blas María Bucheli, Juan Ramón Bucheli, Salvador Ortiz, Mariano de Guevara (secretario) y Joaquín Zapata y Porras (secretario de gobierno). “Acta del cabildo" (Pasto, 28 de mayo de 1822). Bolívar Usobiaga, El libertador y el tratado en Pasto, 28-29.

39. Dada la extensión del documento, en este artículo solo se alude a los aspectos más significativos, teniendo como referencia el documento titulado "Proposiciones-Respuestas". Confesiones de Basilio García. En Bolívar Usobiaga, El libertador y el tratado en Pasto, 34-36. 
especificaciones, contenidas en los Artículos sexto ${ }^{\mathbf{4 0}}$ y décimo ${ }^{\mathbf{4 1}}$. En lo referente al Artículo sexto, se añadió que "Los vecinos de Pasto, sean nativos o transeúntes, serán tratados como los colombianos más favorecidos, y gozarán de todos los derechos de los ciudadanos de la república y llevarán al mismo tiempo las cargas del estado como los demás ciudadanos de la república"42.

Independientemente de que dichos acuerdos no se hubieran cumplido, muestran los intereses de la elite de gobierno local; el origen de otro tipo de discurso, a través del cual se puede percibir la forma en que la élite republicana ${ }^{43}$ asumía el poder de otorgar derechos e imponer deberes a la población de la ciudad de Pasto, como parte de la nueva estructura de poder que el Estado, como institución, había establecido, a partir de la Constitución de 1821, y el ejercicio de una forma de gobierno fundamentado en la división de los poderes: el Legislativo ${ }^{44}$, para promulgar y derogar las leyes; el Ejecutivo ${ }^{45}$, para administrar la paz y la guerra, ejercer la soberanía y la seguridad del territorio, y el Judicial ${ }^{46}$, para administrar la justicia, resolver los conflictos e intereses individuales y castigar los delitos. Así, la rendición de la ciudad, por medio de las capitulaciones, reconfiguraba una relación de poder y constituía el inicio y origen de otra forma de gobernar, administrar y ejercer el poder en manos de los criollos, a los que anteriormente se había excluido del ejercicio del poder político colonial.

\section{EL EJERCICIO DEL PODER Y EL USO DE LA VIOLENCIA: TEMOR Y ORDEN}

La violencia ejercida durante esta época permite articular el temor como parte del ejercicio del poder y de la sociedad pastusa:

El miedo colectivo, esa relación que la sociedad establece con miedos básicos, que reposan en los niveles instintivos de la naturaleza humana, se derivaba

40. “Artículo sesto. Que así como se garantizan las personas y bienes de la tropa veterana y vecinos de Pasto, éstos y todos los que existen en él, aun cuando no sean nativos de allí, no podrán ser destinados en ningún tiempo a cuerpos vivos, sino que se mantendrán como hasta aquí en clase de urbanos, sin que jamás puedan salir de su territorio; que a los emigrados se les de su pasaporte para retirarse al seno de sus familias; y que atendiendo a la pobreza de Pasto y a las grandes erogaciones que ha sufrido durante la guerra, sea exenta de toda pensión". Documento "Proposiciones-Respuestas". Confesiones de Basilio García. En Bolívar Usobiaga, El libertador y el tratado en Pasto, 35.

41. "El libertador no tiene facultad para decidir con respecto al establecimiento de la Casa de la moneda y amonedación, correspondiendo estas atribuciones al Congreso general, al cual podrán ocurrir los habitantes de Pasto a solicitar esta gracia directamente, ó por medio de sus diputados en el Congreso". Documento "Proposiciones-Respuestas". Confesiones de Basilio García. En Bolívar Usobiaga, El libertador y el tratado en Pasto, El libertador y el tratado en Pasto, 36

42. "Proposiciones-Respuestas". (Cuartel general libertador de Berruecos 6 de junio de 1822) y (Cuartel general Libertador en Pasto, 8 de junio de 1822). En Confesiones de Basilio García. En Bolívar Usobiaga, El libertador y el tratado en Pasto, 35

43. La elite republicana que firmó las capitulaciones en Berruecos el 6 de junio de 1822, la conformaron Pantaleón Hierro, Miguel Retamar, José Gabriel Pérez, Vicente González y, en el Cuartel general en Pasto, el 8 de junio, aprobaron y ratificaron el tratado Basilio García y Simón Bolívar. “Confesiones de Basilio García”. En Bolívar Usobiaga. El libertador y el tratado en Pasto, 35.

44. Cuerpo de Leyes de la República de Colombia 1821-1827, 10.

45. Cuerpo de Leyes de la República de Colombia 1821-1827, 17.

46. Cuerpo de Leyes de la Republica de Colombia 1821-1827, 19. 
a la emergencia de múltiples miedos de sofisticada constitución que — de acuerdo con el desarrollo material, social o mental de las sociedades- se van materializando o desapareciendo ${ }^{47}$.

La tensión social, política y económica que caracterizó a la sociedad de Pasto durante esta época permite articular el uso de dos tipos de temor: a la muerte y a la alteración del orden social y político.

Desde la concepción más básica, el temor se define como la angustia por un riesgo o daño real o imaginario, recelo o aprensión que alguien tiene de que le sucediera algo contrario a lo que desea ${ }^{48}$, lo que deriva la existencia de múltiples $\operatorname{tipos}^{49}$, uno de ellos el temor a la muerte. Desde el punto de vista judeocristiano, la muerte encarna "la máxima expresión del miedo en el ser humano, ya que significa la culminación de su existencia y está asociada a la incertidumbre del más allá"; ${ }^{50}$ en este sentido, el papel del clero fue determinante y, desde su discurso, se puede calibrar el ejercicio del poder a través de las ideas y la producción de los imaginarios del pueblo frente a la muerte.

Entre las comunicaciones que el obispo enviaba a los curas de los pueblos estuvieron las proclamas; el mismo obispo expresó: "una de las proclamas que les mandé con las noticias de Guachi, y concediéndoles quarenta días de indulgencia por cada hora que se emplease en perseguir al enemigo e indulgencia plenaria para la hora de la muerte, invocando el dulcísimo nombre de Jesús",51 lo que permite mostrar un fenómeno que siempre ha estado presente en el subconsciente de los individuos y de las sociedades judeocristianas, el temor individual y colectivo a la muerte.

En este caso, ejercer el poder y la administración del perdón, la culpa y alivianar el espíritu de los feligreses tenía su utilidad práctica, expresada de manera concreta en "una hora de persecución por 40 días de indulgencia o la indulgencia plenaria a la hora de la muerte en el nombre de Jesús". Así, el ejercicio del poder sobre esos temores humanos e imaginarios tuvo un uso perverso, como parte de una estrategia calculada para guiar la conducta de la población "ignorante", iletrada

47. Fernando Rosas Moscoso, "El miedo en la historia: lineamientos generales para su estudio". En: El miedo en el Perú. Siglos XVI al XX, ed. por Claudia Rosas Lauro (Lima: Fondo Editorial Pontificia Universidad Católica del Perú, 2005), 24

48. Diccionario de la lengua española, http://dle.rae.es/?id=PDGS53g. (12 de diciembre de 2016).

49. Fernando Rosas Moscoso presenta una tipología de los temores en la Historia, al utilizar el concepto de subversión, debido - según el autor - a que esas expresiones concretas de temor se ligan íntimamente a la subversión del orden, de la armonía o del equilibrio en diferentes planos, entre los que señala: la subversión al orden natural, la subversión de la salud, la subversión del orden sociopolítico, la subversión del orden espiritual, la subversión de la realidad y la subversión globalizada. Fernando Rosas Moscoso, "El miedo en la historia: lineamientos generales para su estudio". En: El miedo en el Perú. Siglos XVI al XX, 27-30.

50. Rosas Moscoso, "El miedo en la historia: lineamientos generales para su estudio". En: El miedo en el Perú Siglos XVI al XX, 24.

51. “Comunicación dirigida por Salvador Jiménez de Enciso a Melchor Aymerich” (Pasto, 5 de enero de 1821), (ANE), Fondo Presidencia de Quito, Caja 234, vol.1, f. 25. 
y subordinada a la aceptación de la tiranía de quienes ejercían el poder desde un orden general de dominación, con el propósito de encauzarla hacia la resistencia.

Con el inicio de la República, empezó a construirse el temor a la alteración del orden social y político desde dos dimensiones: en el pueblo, como producto de toda forma de violencia ejercida para someter, reprimir y establecer el orden, donde la elite local generaba el temor y, también, el temor en la elite local hacia el pueblo, al que se consideraba alterador del orden.

Después de la Batalla de Bomboná (el 7 de abril de 1822), Simón Bolívar envió una advertencia amenazadora a Basilio García, que permite poner en perspectiva la violencia ejercida por el ejército realista sobre el republicano, la molestia de Bolívar, la forma en que la asume, con el derecho a tomar represalias y lo que le esperaba al pueblo pastuso si no llegaba a capitular; al respecto expresó:

Nosotros tenemos derechos para vindicar las infracciones atroces que se hicieron en el armisticio de Trujillo; tenemos derecho para tomar represalias por el asesinato cometido contra el teniente coronel Simón Muñoz, ordenado por V.S., (...) la muerte de este individuo está tan calificada, que ya V.S. no tiene poder ni aun para destruir a todos los testigos del caso. Tenemos derecho para vengar el asesinato de nuestro hospital de Miraflores. La muerte de nuestros enfermos en la Cuchilla del Tambo, el capitán Ledesma y tres más de sus compañeros, asesinados después de rendidos; el asesinato vil y a otros de muchos de nuestros retrasados y enfermos que hemos visto atados a árboles y decapitados. Tenemos derecho para tratar a todo el pueblo de Pasto como prisionero de guerra, porque todo él, sin excepción de una persona, nos hace la guerra, y para confiscarles todos sus bienes como pertenecientes a enemigos. Tenemos, en fin, derecho a tratar a esa guarnición con el último rigor de la guerra, y al pueblo, para confinarlo en prisiones estrechas como prisionero de guerra, en las plazas fuertes marítimas, y todo su territorio secuestrado por cuenta del fisco. Si V.S. lo que desea es esta suerte a las tropas y pueblos de su mando, bien puede contar con ella; y si V.S. quiere evitar una catástrofe semejante, tiene que reconquistar a Colombia, o someterse a una capitulación ${ }^{52}$.

La ocupación de la ciudad, a finales de 1822, se caracterizó por prácticas violentas y brutales. Referirse a esas prácticas, a partir de los testimonios de quienes de algún modo hicieron parte de esa época, se justifica en la medida en que permite una aproximación al sufrimiento al que se sometió a la población. Una de las experiencias más conocidas es la toma de la ciudad por Antonio José de Sucre, en diciembre de 1822, sobre la que José María Obando expresó:

No sé cómo pudo caber en un hombre tan moral, humano e ilustrado como el General Sucre, la medida altamente impolítica y sobremanera cruel, de entregar aquella ciudad, a muchos días de saqueo, de asesinatos y de cuanta iniquidad es capaz la licencia armada: las puertas de los domicilios se abrían con la explosión de los fusiles para matar al propietario, al padre, a la esposa,

52. “Carta de Simón Bolívar dirigida a Basilio García” (Cuartel general del Trapiche, 23 de mayo de 1822). En Bolívar Usobiaga, El libertador y el tratado en Pasto, 20-21. 
al hermano y hacerse dueño el brutal soldado de las propiedades, de las hijas, de las hermanas, de las esposas; hubo madre que en su despecho saliese a la calle llevando a su hija de la mano para entregarla a un soldado blanco, antes que otro negro dispusiese de su inocencia: los templos llenos de depósitos y de refugiadas, fueron también asaltados y saqueados; la decencia se resiste a referir por menor tantos actos de inmoralidad ejecutados en un pueblo entero que de boca en boca ha trasmitido sus quejas a la posteridad ${ }^{53}$.

El relato es claro para imaginar el sufrimiento que la población experimentó y la violencia ${ }^{54}$ que caracterizó el ejercicio del poder republicano, como una forma de castigo o represalia, anunciada por Bolívar. Todo acto de violencia y crueldad se justificó para lograr la seguridad y ejercer la soberanía en el territorio ${ }^{\mathbf{5 5}}$.

El temor no solo estuvo presente en la inmensa mayoría de la población, sino también formó parte de la autoridad republicana, consciente de que la dominación del pueblo no era total y absoluta; el temor al riesgo latente de una nueva revuelta fue constante, lo que generó reacciones más violentas para someter, como lo señala Scarlett O'Phelan Godoy: "si bien la plebe era despreciada, hay que admitir que también era temida"56. El temor a la alteración del orden social y político en la ciudad se definía por la relación de la población con la autoridad republicana; el pueblo pasó a ser el alterador del orden y la elite de gobierno local, prisionera de sus propios intereses, adoptó medidas para contener a la masa que, en un momento dado, había sido su aliada.

A nivel del lenguaje es común encontrar en la documentación palabras como "revoltosos", "facciosos", "enemigos del orden" y, también, se identificaba el periodo entre 1823 y 1827 como la "época del bochinche y la revolución”, detalles que podrían considerarse anecdóticos y permiten identificar la producción de sentidos y actitudes respecto al pueblo.

El temor frente al riesgo de la desobediencia se expresó en las medidas adoptadas por el Cabildo a partir de 1823, que consistieron básicamente en perseguir y remitir lejos de la ciudad a los "enemigos del orden", para conseguir

53. José María Obando, Apuntamientos para la historia (Lima: Imprenta del Comercio, 1842), 27.

54. El 20 de enero de 1823 el pueblo fue convocado para jurar las instituciones republicanas (...), Salom y Flores apresaron a 1200 pasteños que remitieron armados al Ecuador y al Perú, fueron precipitados a las aguas del rio Guaitara, catorce pares de hombres (...) atados por la espalda, el General Flores fusiló en Siquitan veintitrés prisioneros e incendió las poblaciones de Siquitan y el pueblo del Rosal del Monte, entre otras prácticas violentas.” En Boletín de Estudios Históricos 3, n² 25 (1829):30.

55. En la correspondencia entre los jefes militares se puede citar una de las formas en que se referían al pueblo y lo sucedido: "Creo que los de Pasto han quedado en estado de no volver a respirar, pues la espurgación ha sido completa (...). Yo no quería que quede alma viviente en Pasto por mas buenos, que sean, sino que se regenere ese País con nueva gente, único arbitrio para que aquellos pueblos sean nuestros amigos”. “Carta de Guillermo Valdiviezo a Juan Paz del Castillo” (Quito, 22 de julio de 1825). Banco Central del Ecuador, Archivo Jacinto Jijón y Caamaño. (BCAJJC). Título: Administración Pública y revueltas independentistas, Código JJC00051, f. 52.

56. Scarlett O’Phelan Godoy, "La construcción del miedo a la plebe en el siglo XVIII". En El miedo en el Perú, Siglos XVI al XX, 124. 
la paz y la tranquilidad 57 . Se ordenó que los curas, en las parroquias, "prediquen la Religión Católica y exhorten a sus feligreses, a la obediencia al Gobierno, amor a las Leyes, y respeto a las autoridades legítimamente constituidas, lo mismo que al Libertador Presidente, Simón Bolívar"58; también, se los previno y encargó para que "vigilen exactamente sobre que no se introduzcan papeles seductores, entre sus feligreses, y que si alguno se introdujere, lo cojan inmediatamente y lo remitan a este Gobierno" 59 .

\section{CONCLUSIONES}

El ejercicio del poder se caracterizó por el uso del consenso de la elite de gobierno local; los miembros del Cabildo dejaron plasmados sus intereses particulares orientados a la conservación de sus bienes, privilegios económicos y las costumbres religiosas; esta negociación y rendición significó el inicio de la adhesión política dentro de una relación subordinada a la administración de la elite republicana.

Los miembros del clero cumplieron un papel fundamental, a través del poder e influencia sobre las ideas y la conducta de la población, un poder articulado con el poder político que, después de movilizar a la guerra, continuó ejerciéndose con el objetivo de promover el orden social, la obediencia y el respeto a la Ley y a la República.

Si bien las capitulaciones marcaron el inicio de una nueva relación de poder con la autoridad republicana, no significaron el fin de la guerra y se podría decir que fueron unos acuerdos distantes de la gran masa que, en última instancia, era la que había soportado y continuaría experimentando el rigor de la guerra y, mientras la violencia ejercida sobre la población aumentaba, se evidenciaba que el proyecto republicano no tenía mucho en común con el pueblo.

57. "Acta Capitular del Cabildo". (Pasto, 23 de mayo de 1823), (IMAHP). Fondo Cabildo de Pasto, Sección Independencia, Caja 11, Libro 1823, f. 18-19.

58. “Comunicación del gobernador Francisco Gutiérrez al Presbítero Toribio Rosero de Zúñiga” (Pasto, 25 de octubre de 1828). Boletín de Estudios Históricos 2, n 18 (1829): 162.

59. “Comunicación del gobernador Francisco Gutiérrez al Presbítero Toribio Rosero de Zúñiga”, 162. 


\section{REFERENCIAS BIBLIOGRÁFICAS}

\section{Fuentes primarias}

Archivo Nacional de Ecuador (ANE), Fondo Presidencia de Quito, Caja 234, Vol. 1.

Banco Central de Ecuador Archivo Jacinto Jijón y Caamaño. (BCAJJC), Quito-Ecuador. Título: Administración Pública y revueltas independentistas, Código JJC00051.

Instituto Municipal Archivo Histórico de Pasto (IMAHP), Fondo Cabildo de Pasto, Sección Independencia, Caja 10, Libro 1819.

Instituto Municipal Archivo Histórico de Pasto (IMAHP), Fondo Cabildo de Pasto, Sección Independencia, Caja 11, Libro 1823.

\section{Bibliografía}

Bolívar Usobiaga, Ignacio. 1980. El libertador y el tratado en Pasto. Sevilla: (s. e.).

Bragoni, Beatriz y Sara E. Mata, comps. 2009. Entre la colonia y la república. Insurgencias, rebeliones y cultura política en América del Sur. Buenos Aires: Prometeo Libros.

Bloch, Marc. 2001. Apología para la historia o el oficio de historiador. México, D.F: Fondo de Cultura Económica. Caldas, Francisco José de. 1917. Cartas de Caldas. Bogotá: Imprenta Nacional.

Castro-Gómez, Santiago. 2010. La Hybris del Punto Cero. Ciencia, Raza e Ilustración en el Nuevo Reino de Granada (1750-1816). Bogotá: Editorial Pontificia Universidad Javeriana/ Instituto Pensar.

Chust, Manuel e Ivana Frasquet, eds. 2009. Los colores de las independencias iberoamericanas. Liberalismo, etnia y raza. Madrid: CSIC.

Corona, María Carmen, Ivana Frasquet, Ivana y Carmen María Fernández, eds. 2009. Legitimidad, soberanías, representación: independencias y naciones en Iberoamérica. Castelló de la Plana, Universitat Jaume I.

Cuerpo de Leyes de la República de Colombia 1821-1827. 1961. Caracas: Consejo de Desarrollo Científico y Humanístico/Universidad Central de Venezuela.

Diccionario de la lengua española, http://dle.rae.es/?id=PDGS53g. (12 de diciembre de 2016).

Echeverri, Marcela. Los Derechos de indios y Esclavos Realistas y la Transformación Política en Popayán, Nueva Granada (1808-1820). Revista de Indias 69, n² 246 (2009):45-72.

Escobar, Jerónimo. “Calidades de la tierra por Fr. (Madrid, 1582), Gobierno de Popayán”, en Fuentes para la Historia Andina, Relaciones Histórico-Geográficas de la audiencia de Quito siglo XVI-XIX, editado por Pilar Ponce Leiva (Quito: Instituto de Historia y Antropología Andina/Abya-Yala, 1992), Vol. 1:334-35.

Febvre, Lucien. Combates por la historia. 1970. Barcelona: Ariel.

Foucault, Michel. Estética, ética y hermenéutica. Obras esenciales. 1999. Barcelona: Paidós, Volumen 3.

Guerrero, Carol y Gerardo Guerrero. 2011. El honor en Pasto durante la Independencia "Ia defensa de la Santa Causa", Pasto: Universidad de Nariño/Ceilat.

Guerrero, Gerardo. Pasto en la Guerra de Independencia 1809-1824. 1994. Bogotá: Tecnimpresores.

Guerrero, Gustavo, Documentos Históricos de los hechos ocurridos en Pasto. 1912. Pasto: Imprenta Departamental.

Gutiérrez Ramos, Jairo. Los indios de Pasto contra la República (1809-1824). 2007. Bogotá: Instituto Colombiano de Antropología e Historia. 
Gutiérrez Ramos, Jairo. Acción política y redes de solidaridad étnica entre los indios de Pasto en tiempos de la Independencia. Historia Crítica 33, (enero-junio 2007), http://www.scielo.org.co/pdf/rhc/n33/n33a02. pdf (10 de octubre de 2012).

López Álvarez, Leopoldo y Sergio Elías Ortiz. Boletín de Estudios Históricos 2, nº 14 (1928): 33-63.

López Álvarez, Leopoldo y Sergio Elías Ortiz. Boletín de Estudios Históricos 2, nº 18 (1929): 161-92.

López Álvarez, Leopoldo y Sergio Elías Ortiz. Boletín de Estudios Históricos 3, nº 25 (1929):1-32.

López Álvarez, Leopoldo y Sergio Elías Ortiz. Boletín de Estudios Históricos 3, nº 32 (1930): 224-56.

Lynch, John. América Latina, entre Colonia y Nación. 2001. Barcelona: Editorial Crítica.

Mamián, Dúmer. "Rastros y rostros del poder en la Provincia de Pasto Primera mitad del Siglo XIX, "Leales a sí mismo"'. Tesis doctoral. Universidad Andina Simón Bolívar de Quito. 2010.

Minaudier, Jean Pierre. Pequeñas Patrias en la Tormenta: Pasto y Barbacoas a finales de la colonia y en la independencia. Historia y espacio. Revista de estudios Históricos Regionales 3, $\mathrm{n}^{\circ} 11-12$ (enero-diciembre, 1987):131-165. En: http://bibliotecadigital.univalle.edu.co/xmlui/bitstream/handle/10893/7432/5.\%20 Peque nas\%20patrias\%20en\%20la\%20tormenta\%20Pasto\%20y\%20Barbacoas\%20-\%20Minaudier\%20 Jean.pdf?se quence $=1$.

Muñoz Cordero, Lydia Inés. El Consejo de Pasto a través de la Historia. 2000. San Juan de Pasto: Universidad de Nariño.

O’Phelan Godoy, Scarlett. 2005. La construcción del miedo a la plebe en el siglo XVIII a través de las rebeliones sociales. En El miedo en el Perú Siglos XVI al XX, editado por Claudia Rosas Lauro, 123-38. Lima: Fondo Editorial Pontificia Universidad Católica del Perú.

Obando, José María. 1842. Apuntamientos para la historia. Lima: Imprenta del Comercio.

Ortiz, Sergio Elías. Agustín Agualongo y su tiempo. 1958. Bogotá: Editorial ABC.

Romero, José Luis. Latinoamérica las ciudades y las ideas. 2014. Buenos Aires: Siglo XXI editores.

Rosas Moscoso, Fernando. 2005. "El miedo en la historia: lineamientos generales para su estudio". En El miedo en el Perú. Siglos XVI al XX, editado por Claudia Rosas Lauro, 23-32. Lima: Fondo Editorial Pontificia Universidad Católica del Perú.

Tovar, Hermes, Jorge Tovar y Camilo Tovar. Convocatoria al poder del número. Censos y estadísticas de la Nueva Granada (1750-1830). 1994. Bogotá: Archivo General de la Nación.

Zarama Rincón, Rosa Isabel. Vida cotidiana en San Juan de Pasto, 170-1810. 2005. Pasto: Fondo Mixto de Cultura de Nariño. 